\title{
A discursividade evangélica e alguns de seus efeitos: laço social, psicopatologia e impasses teóricos e transferenciais
}

\author{
Evangelical discourse and some of its \\ effects: Social bond, psychopathology and \\ theoretical and transferential impasses
}

\author{
Gabriel Inticher Binkowski*1 \\ Miriam Debieux Rosa*2 \\ Thierry Baubet*3
}

Discutimos neste artigo a presença do discurso evangélico entre pacientes de serviços de saúde mental e de atenção psicossocial, nas características de tal fenômeno religioso e de suas possibilidades de transformar a vida de sujeitos, famílias e grupos ao ligá-los a uma modalidade bastante peculiar de discursividade religiosa. Como viemos pesquisando essas questões na França e no Brasil, propomos duas vinhetas clínicas (de um caso acompanhado em cada um desses países) para pensar sobre o tipo de transformação subjetiva e psíquica que esse laço religioso provoca, em como ele afeta o enlace transferencial e nas dificuldades que o mesmo pode provocar para profissionais que atuam sobre a subjetividade. Para isso, levantamos alguns dos pontos nodais das leituras psicanalíticas sobre religião e religiosidade, naquilo que aparece da coisa religiosa na gênese da vida psíquica, no sujeito, nos grupos, na cultura e na política.

Palavras-chave: Evangélicos, psicanálise, religião, conversão

*1, 2 Universidade de São Paulo - USP (São Paulo, SP, Brasil)

${ }^{* 3}$ Université Sorbonne Paris Nord (Paris, França). 


\section{Introdução}

Sustentamos neste artigo a práxis da pesquisa em psicanálise e psicopatologia. Com ela, entendemos que é possível e válido calibrar a mira na compreensão de fenômenos religiosos, que se configuram como conjuntos históricos, semióticos e materiais que fomentam discursividades e, portanto, têm implicação psíquica e política. Tomamos a discursividade evangélica das comunidades e igrejas pentecostais e, sobretudo, neopentecostais, com o intuito de explorá-la à luz da lógica conceitual e dos métodos propostos pela psicanálise.

Consideramos que esse fenômeno deve ser investigado em nosso campo, por implicar transformações subjetivas importantes na vida de sujeitos. No caso de sujeitos que se submetem a nossas práticas clínicas, somos seguidamente confrontados com esse gênero de configuração existencial, grupal e cultural, encontrado em bolsões psicossociais onde atuam serviços por onde se embrenham profissionais cuja prática se define como psicanalítica (e aqui falamos de dispositivos de saúde mental, de educação, da assistência social, da justiça). São bolsões psicossociais de comunidades marcadas por modalidades de desamparo, seja desamparo de governo ou mesmo discursivo (Rosa, 2016). É onde costumam aparecer novos tipos de afetos que levam o sujeito a despossuir os predicados com os quais se identificava na busca de outros que possam levá-lo a confrontar sua impotência (Safatle, 2018). A discursividade de tipo evangélica, particularmente neopentecostal, parece funcionar nessa via de produção subjetiva. 


\section{ARTIGOS}

Há diferentes possibilidades para uma abordagem da psicanálise quanto à questão do religioso (da presença da coisa religiosa ${ }^{1}$ na vida psíquica). Propomos que um fato religioso pode ser encarado a partir de três perspectivas complementares. Na primeira, há a teia emaranhada por simbólico e imaginário que é oferecida por um sistema religioso. Em nosso objeto de estudo, trata-se de uma modalidade de monoteísmo cristão que se decalca entre grupos e correntes evangélicas hoje. Na segunda perspectiva, pode-se falar do tipo de configurações grupais e culturais que uma corrente religiosa enseja, no tipo de relação com as escrituras (nas formas de exegese e transmissão predominantes), em como se forjam, se ampliam e se reproduzem esses grupos e suas relações com outros aspectos da cultura - como o fazer político de um país, a relação com as mídias, com os objetos da cultura popular.

Por fim, e é esta via que trilharemos neste trabalho, a terceira perspectiva privilegia escutar como essa teia simbólico-imaginária evangélica funciona na vida de um sujeito em sua singularidade, como isso aparece numa constituição de constelação (e narrativa) familiar e de que maneira a relação de um sujeito com sua realidade é transformada (Binkowski, 2015). Isso pode ser lido decupando os significantes que se decalcam na constituição dos sintomas (encontrados na clínica) e que ensejam tramas discursivas que operam identificações, laços sociais e que desvelam certos aspectos do real (no sentido lacaniano) para o sujeito.

Pensamos que essa terceira possibilidade de leitura é fundamental para profissionais da clínica e do cuidado. Estamos cotidianamente imersos em universos simbólicos da saúde mental e de comunidades onde tais fenômenos religiosos são centrais na vida sociocultural de pacientes, famílias, enfim, do próprio tecido comunitário, social e institucional de uma dada população (Binkowski \& Baubet, 2012).

Em suma, discutiremos sobre as questões trazidas por pacientes evangélicos neopentecostais, sujeitos que portam uma espessa referência a

${ }^{1}$ Fazemos menção à coisa religiosa, em vez de falar em dimensão religiosa, para salientar algo que fora teorizado por Jean-Michel Hirt à propósito da presença da questão religiosa na obra de Freud: o interesse de Freud, e da psicanálise, pela religião se dá pela verdade que ela veicula, verdade clivada entre sabido e insabido, entre verdade histórica e material (Hirt, 2006), algo predominante na teorização freudiana no texto "Moisés e o monoteísmo" (Freud, 1939). As religiões, em suas modalidades de transmissão via ritos e tradições, são pontuadas por objetos, representações, signos etc., que funcionam como depositários de ficções materiais e histórias que produzem efeitos "de verdade" sobre os sujeitos, garantindo assim sua manutenção, mantendo também o recalcado. 
esse tipo de religiosidade hoje tão popular, apesar de ainda bem desconhecida e distante da realidade social e simbólica da maioria dos profissionais da clínica. Problematizaremos algumas questões manifestas e outras implícitas por meio de duas vinhetas clínicas extraídas de nossa experiência de pesquisa e de atuação profissional em realidades bem distintas, no caso, no Brasil e na França.

\section{A problemática e aspectos metodológicos}

Apesar de toda a diferença encontrada em relação à organização social, o modelo cultural e as próprias referências contextuais trazidas por pacientes oriundos de realidades distintas (como sujeitos africanos e asiáticos que se convertem no périplo migratório na Europa), as igrejas evangélicas de tipo neopentecostal mostram certa constância ao redor do planeta, ofertando cuidado social e espiritual a populações desassistidas do poder público (Plunkett, 2009). Elas promovem um tipo sólido de relação entre sujeito e comunidade religiosa, entre indivíduos e autoridades religiosas, forjando um laço social singular.

Aqui pensamos o laço social como discurso (Lacan, 1972-73/1975), que opera na produção de sujeito, de subjetividade. A religião brota a partir daquilo que mobiliza no ser humano seu desamparo fundamental (Hiflosigkeit), funcionando pela oferta da imagem de uma deidade (geralmente um pai) que consola frente ao desassossego da vida, da natureza e do destino, como já pontuava Freud (1930/2015). Por conta disso, a religião fomenta entre fiel e autoridade religiosa (seja um pastor, a igreja, comunidade) uma relação que é transferencial, na medida em que o sujeito ali atualiza o seu estado ontológico inacabado perante um Outro que lhe garante um tanto de consolação e conforto (Dufour, 2005).

A modalidade de relação que uma religiosidade do tipo evangélico (neo)pentecostal promove é bastante espessa, com o sujeito reinterpretando sua vida, em seus aspectos biográficos e experienciais, a partir de certo conjunto léxico e semântico. Há, portanto, transferência para com essa presença religiosa, presença maciça a ponto de se intrometer na própria constituição da transferência entre paciente e terapeuta, quando esses sujeitos se tornam usuários de serviços de saúde mental ou de cuidado psicossocial. Afinal, na transferência, trata-se de uma atualização dos investimentos libidinais elementares (Freud, 1912), o que é chave para entendermos sobre o funcionamento da relação entre um sujeito e seu pertencimento religioso. 
No caso, essa intromissão da discursividade religiosa na transferência é uma constatação empírica que tínhamos ao iniciar esta pesquisa, e que compartilhávamos com outros colegas, tanto pesquisadores quanto clínicos em serviços de cuidado psicossocial. Destacamos então dois casos em que tomar o aspecto religioso se mostrou fundamental para pensar nos elementos que apareciam no caso (nos sintomas, no desvelamento da história do sujeito, nas relações familiares) como também em certos fenômenos que transpareciam na relação transferencial estabelecida entre sujeito e terapeuta ou entre sujeito e espaço institucional de cuidado.

Nas vinhetas com as quais pensamos esses aspectos referentes à religião, tentou-se decalcar algo defendido por Siqueira \& Queiroz (2014) a propósito da marca do caso: vinhetas clínicas em que o caso é abordado a partir de seu ponto nevrálgico. Logo, a trama do caso se erige por uma lógica de composição de elementos cujo orientador metodológico é o movimento transferencial que ali transparece. Dali pode se "extrair", ou melhor, produzir teoria. Apoiando-se em casos oriundos de "mundos" tão diferentes, Brasil para o primeiro, França/Haiti para o segundo, evocamos a ideia de Carneiro (2018) sobre o uso de casos múltiplos como forma de nomear algum mal-estar recorrente e que prevaleça na relação entre as marcas dos casos, mesmo que guardando a abertura para certos afastamentos contextuais e posições singulares do sujeito frente ao Outro.

Além disso, cabe ressaltar que os casos se mostram estruturalmente diferentes. Contudo, a preocupação aqui não é de diagnóstico estrutural, mas quanto ao aparecimento da coisa religiosa no caso e na tomada desse elemento para desvelar algo que se tornava predominante na relação do sujeito para com o Outro e, justamente, fundamental para ler a constituição transferencial, seja nos fenômenos do sujeito seja junto aos profissionais da clínica e nas próprias instituições de acolhimento.

\section{Joel, das fugas a uma busca}

Anos atrás, quando ainda não tínhamos nos aproximado do campo de pesquisa dos fatos religiosos, ficamos responsáveis pelo acolhimento num Centro de Atenção Psicossocial (CAPS) de um jovem de 18 anos recém-completados, Joel (nome fictício). A dificuldade da acolhida desse jovem se devia a uma longa história de institucionalização e fugas. 
Desde cedo frequentando abrigos e espaços de internação psiquiátrica, o paciente, sempre fortemente medicado por conta de uma sintomatologia esquizofrênica comprometedora, teve uma infância de perdas e violências. Sem pai conhecido, com uma mãe também paciente de serviços psiquiátricos, ele fora cuidado pela avó materna. Quando do início de nosso contato no CAPS, sabíamos apenas de alguns pontos da história do jovem, cuja circulação institucional atravessara diversas instituições em menos de dez anos, fugindo de cada uma delas e refugiando-se num grande parque de sua cidade. Ali ele fora estuprado muitas vezes, enfrentando inúmeras situações de vulnerabilidade e contraindo tuberculose. Ademais, seu grosso prontuário, permeado de notas sobre o uso e a variação de psicofármacos receitados, contrastava com a pobreza de informações subjetivas sobre o paciente: nenhuma fala anotada, poucas informações "pessoais".

Em nosso primeiro contato, o mal-estar que produzia na equipe era evidente: de um corpo fragilizado pela convalescência da tuberculose e por uma constante anorexia (ele só não recusava ingerir sucos) surgia uma incrível força muscular, com gesticulações, estereotipias, saltos e vocalizações. Os pormenores de sua fala encenavam uma estranha interação 250 entre passagens bíblicas recitadas e enunciados em voz gutural. A repetição desses "diálogos" apresentava poucas variações: falas como aquelas eram comuns em tribunas de igrejas evangélicas, com suas promessas de cura e relatos de frases ditas por demônios ou outras entidades malignas. A cena era ainda composta por pulos, quedas, numa teatralidade que a todos intrigava, profissionais e usuários. Afinal, o que o paciente emulava era muito próximo de rituais de exorcismos e de sessões de cura como as vistas em certas igrejas: ele encenava seu sofrimento pelo próprio corpo, reagindo a algo que se movia dentro de sua barriga, que lhe provocava muita dor. A cada repetição, caía no chão, levantando com joelhos, cotovelos e mãos ensanguentados.

Com o passar dos meses, fomos conseguindo sair do serviço com Joel, caminhando pela cidade e aproveitando de momentos de deambulação onde ele se mostrava muito colaborativo para conversas. Nossos passeios pareciam guiados por algum tipo de busca geográfica: olhando certos tipos de prédios, ele pedia informações na rua sobre o caminho para uma determinada região da cidade. Numa dessas saídas, encontramos uma sede da Igreja Universal do Reino de Deus que ele frequentava com sua avó durante a infância e a adolescência, nos períodos em que não estava em abrigos ou em espaços de internação psiquiátrica. Tomado de exaltação e alegria, Joel foi interrogando frequentadores da igreja até chegar ao púlpito para falar com o pastor: "O 
senhor lembra de mim? Eu vinha aqui com a minha vó, para me curar do diabo...". Com um impávido tom de serenidade, o jovem pastor respondeu: "Desculpa, eu sou novo aqui.".

Desse encontro sucederam-se outras saídas, tendo por objetivo a procura de alguém que por ventura pudesse reconhecê-lo. No encerramento do trabalho com Joel, meses depois, quando ele iria ser transferido para outra instituição de cuidados, havia uma formação delirante mais ou menos estabilizada: o jovem esperava um renascimento de sua alma em seu próprio corpo, quando a colomba do Espírito Santo nele adentrasse e trouxesse o alívio dos sintomas pelo processo de conversão religiosa. Ainda, sua anorexia remetia a esses dias de espera na igreja com a avó, quando ela não lhe dava nada para comer a fim de não alimentar o demônio que habitava seu ventre. Se o rapaz estivesse mais fraco, o exorcismo seria mais efetivo, e o corpo tomado pela entidade maligna poderia ser enfim habitado pela presença de Cristo.

Malgrado a aparência um tanto fantástica desse caso, nele reconhecemos elementos frequentemente encontrados tanto em casos de psicose como uma certa discursividade popular, ligada ao mágico e ao religioso e que faz parte do cotidiano da vida de boa parte das pessoas no Brasil. Como apontara Freire Costa (1989): "Boa parte da clientela que afluía aos ambulatórios psiquiátricos queixava-se de um mal-estar cuja sintomatologia driblava a nosografia tradicional: a doença de nervos" (p. 17), justificando que clínicos devam estar atentos à complexidade simbólico-imaginária do que erige a experiência subjetiva de populações que atendemos e da semântica e representações usadas para descrever seu mal-estar. O que defende Freire Costa é que o campo dos significantes e do sentido é uma construção coletiva, pública e socializada. Como já chamava a atenção Lacan (1956/1966) para alguns lembretes triviais para a prática da psicanálise, sobre o que ocorre nela, é necessário saber de onde vem a palavra. No caso da coisa religiosa, quando ela se apresenta, isso sempre se dá por meio de palavras, de significantes que aparecem num espaço transferencial, para com um terapeuta ou numa instituição. Negar a força instauradora desses significantes na realidade psíquica é recuar na tarefa de escuta que nossa ética nos impele sustentar.

\section{Jane, um passo à frente das clivagens}

"Eu tive uma espécie de alucinação durante uma sessão... Eu podia ver Jane dividida em duas, mas era um tanto embaçado, como se meus óculos 
estivessem com as lentes sujas. Era como se houvesse dois buracos no lugar dos olhos, fossas negras de onde escorria algo como petróleo, ou sangue negro. Duas chagas, isso."

Esse relato nos foi confidenciado por um colega psicanalista, psicólogo-clínico responsável por atender num enquadre psicoterapêutico uma jovem adulta que frequentava uma Maison des Adolescents (serviço multiprofissional de acolhimento e atendimento psicossocial para jovens de 12 a 21 anos) ligada a um hospital da região metropolitana de Paris. Era uma jovem que tínhamos encontrado em outros dispositivos de atendimento desse serviço, do qual ela era usuária por dois anos. Jane fora encaminhada pela unidade de emergência do hospital. À época, ela estava com 17 anos e apresentava um quadro de crises de pânico, estava sem dormir por dias e sofria de anemia severa. Ela havia desenvolvido uma importante anorexia desde sua chegada na França.

Durante o acolhimento na Maison des Adolescents, descobriu-se que Jane entrara na França vinda do Haiti, seu país de origem, usando o passaporte de sua prima - algo bastante comum em casos de clínica em situação transcultural. Num primeiro contato com aqueles que seriam seus 252 familiares, entendemos que ela havia sido enviada para a França um ano depois do grande terremoto de 2010 por iniciativa da mãe, que conhecia uma senhora disposta a acolher a filha, que, em troca, faria os trabalhos domésticos da casa.

Dois anos depois, Jane já vivia com a mãe, que também pôde imigrar para a França, e tinha uma rotina que ia dos estudos de enfermagem à frequentação de uma pequena congregação evangélica da região metropolitana de Paris. Era uma das chamadas "igrejas da migração", como alguns pesquisadores dos fatos religiosos costumam chamar, organizada em torno da autoridade de um pastor haitiano, com cultos e atividades em língua crioula haitiana e com rituais que lembravam práticas de vodu.

Jane, estudante e religiosa, já se mostrava com uma vida bem mais organizada do que no início. Ao longo do seu tempo de tratamento (seja em atendimentos com psicólogo, com psiquiatra, assistente social ou nos espaços grupais de convivência), foi possível desenovelar uma trama fortemente ancorada pela religião e por uma mãe que se tomava como uma autoridade espiritual sagrada.

Jane cresceu clivada entre a autoridade da mãe e do avô materno, esse um pastor evangélico com capacidade de operar milagres, e um pai sobre o qual a mãe e ela falavam de forma extremamente sexualizada: ele estava 


\section{ARTIGOS}

sempre fora de casa, desaparecido por ter "encontrado outras mulheres" e embrenhado em práticas religiosas vodu. Muitas vezes, ainda, ela citava a presença de um vizinho, um senhor mais velho que tomava conta dela e que aparecia seguidamente nu, seja com outras mulheres ou se oferecendo para o olhar da menina: "eu sentia como se ali pudesse ter acontecido um abuso, um sexual mais violento, não passível de compreensão para uma Jane criança. Essa figura, esse senhor, aparecia em seus sonhos, pesadelos, um pouco como um duplo desse pai desaparecido, mas também como uma espécie de demônio, figura maligna que a assustava e a excitava" (fala do terapeuta).

Conversando sobre sua experiência religiosa, impressionava a presença da mãe: Jane a descrevia como alguém que herdara um dom espetacular, que enxergava signos proféticos e que previu para a filha um casamento e uma carreira na área da saúde. Adequando-se a essas leituras maternas, Jane noivara com um rapaz da igreja e tinha iniciado estudos em enfermagem.

Aos poucos, em diversas conversas em espaços de convivência na instituição, ela falava de seus sintomas somáticos, de uma "bola que se deslocava pelo abdômen até o pescoço", algo que preenchia o interior e que a deixava estufada e sufocada. Nisso podíamos escutar uma grande similitude em algo que a mãe costumava lhe repetir, que era a história do apóstolo Pedro, que, ao ver Jesus andando sobre as águas, dá um passo para fora do barco em meio a uma tempestade e acaba afundando, por falta de fé. Jane dizia repetidas vezes que sua mãe citava esse relato bíblico para convencer a filha da importância de não confiar na palavra divina ou do pastor, e sim na dela.

Quando interrogamos Jane sobre sua conversão (cujo relato ela preparara para o dia de seu batismo), ela dizia que era algo que fora acontecendo desde a infância: "na igreja, lá no Haiti, sempre diziam que aquele que estava sentindo Jesus dentro de si deveria fechar os olhos e dar um passo à frente. Eu sempre dava, e isso ia me estufando, fazendo com que eu sentisse algo dentro de mim. Só que eu nunca soube se era algo divino, o Espírito Santo, ou se havia alguma entidade maligna, um espírito, alguma maldição que vinha do meu pai". Na época do batismo — os evangélicos realizam esse rito por imersão em água —, Jane temia se afogar na piscina colocada sobre o palco da igreja, "se eu me afogar e passar mal, quer dizer que eu não vivi uma verdadeira conversão?".

Éramos bastante próximos do psicoterapeuta de Jane. Ele chegou a discutir conosco sobre o seu mal-estar durante os atendimentos, sobre a rivalidade com a mãe da garota: "minha palavra é percebida como alteridade maligna, algo que potencialmente pode envenená-la. Na verdade, atendê-la 
faz com que eu pense na minha própria mãe, aquela coisa de uma mãe católica italiana... até bem tarde, tipo 11 anos, eu pensava que minha mãe podia me vigiar em todo o lugar, ver meus pensamentos e saber que eu tinha ereções e desejos sexuais".

Esse foi um caso clínico que mostra que a coisa religiosa se localiza nesse espaço psíquico e subjetivo repleto de elementos proteiformes, nessa confusão entre eu e Outro, onde habita essas imagens de corpo fragmentado, lá onde o sentido e o não sentido se entrelaçam, colocando em cena uma série de formações das quais podemos falar como sendo desse encontro com um real, com o indizível e o não simbolizável (Binkowski, 2015). Tanto na sintomatologia de Jane como nos fenômenos produzidos no espaço transferencial e na forma de se apresentar perante os outros, havia uma predominância de clivagens, as quais davam vazão a esses elementos proteiformes e aparentemente desnudados de sentido. Era aqui que o discurso religioso intervinha, como que numa tentativa de estar à frente dessas aberturas do real.

Se as religiões são, já apostavam Freud e Lacan — cada um com uma linguagem diferente — máquinas que dão sentido a experiências 254 de desamparo e de sofrimento, é porque as religiões, enquanto grandes compostos simbólico-imaginários, trabalham incessantemente nesses territórios psíquicos e subjetivos que são aqueles da indistinção entre eu e outro, ali onde o falante se submete aos auspícios da linguagem e da significação, naquilo que compreende os elementos arcaicos do psiquismo e que faz parte da gramática dos mitos, dos textos religiosos e de todo um conteúdo que é transmitido pelas tradições religiosas e que reaparece nos novos movimentos religiosos de forma um tanto extemporânea. É por isso que salientamos que esses elementos proteiformes (re)aparecem nesse tipo de situação, que é o do trabalho clínico e psicossocial com sujeitos cujas tramas subjetivas são perpassadas pela coisa religiosa.

Nos casos tanto de Jane quanto de Joel, identificamos configurações subjetivas, sintomáticas e de laço social que despertam muita coisa na transferência que temos com os pacientes e na própria transferência institucional. Jane seguidamente discutia conosco e com jovens dos grupos terapêuticos a propósito de "seu segredo" (outra clivagem): apesar de ir à igreja todos os domingos, de envolver-se em tantas atividades, de ser objeto de uma profecia anunciada por sua mãe onde ela se mostraria como possuidora do dom de curar com as mãos (o que fora um dos motivos da eleição do curso de enfermagem), Jane confessava sofrer, "eu trago o mal 


\section{ARTIGOS}

dentro de mim, sou cheia de problemas, essa coisa dentro do meu corpo, que é minha e que também não me pertence... só que ninguém na igreja pode saber disso, dessa infelicidade, dessa verdade". Já Joel era às vezes tratado como abjeto pelas equipes de cuidado, que pouco suportavam a loucura do que ele colocava em cena. Foi ao trazer um pouco da lógica religiosa de seu discurso que um tipo de acolhimento pôde ser feito. Em ambos os casos, havia uma discursividade evangélica (neopentecostal) que precisou ser alcançada e tomada como parte da fabricação da subjetividade, do laço social, dos sintomas e da transferência que esses pacientes produziam.

\section{Da discursividade evangélica}

As igrejas evangélicas neopentecostais têm recebido cada vez mais atenção das mídias e de pesquisadores das ciências humanas e sociais. Até os anos 1970-1980 estes grupos eram tidos como um tanto deslocados de aspectos centrais da modernidade em seus hábitos morais, gostos estéticos e uso das tecnologias. Isso se transformou com a virada de século: os grupos evangélicos deixaram para trás a feição mais fundamentalista que pregava o abandono da sociedade moderna e de seus prazeres, como a música, a televisão, o futebol e celebrações populares. Incorpora-se à ética e à estética evangélica aquilo que hoje caracteriza a vertente neopentecostal: apelo popular nas práticas coletivas, gosto pelo sucesso financeiro (e a consequente ascensão de classe) e o bem-estar físico e psicológico na experiência individual (Aubrée, 2013).

O movimento neopentecostal ganhou o mundo por meio de pastores midiáticos, música gospel, celebrações envolvendo oração, cura e poder que contam com milhares de fiéis. Houve ainda futebolistas convertidos que dedicaram suas conquistas a Jesus (atribuindo sua transformação pessoal e melhora de desempenho esportivo à prática religiosa) e uma celebração do sucesso financeiro pessoal como marca de um pertencimento religioso bem-sucedido (Fath, 2006; De Chalus, 2014).

No início do milênio, o número de evangélicos chegava a 500 milhões ao redor de todo planeta (Mercier, 2012). Apesar da variabilidade litúrgica, confessional e das configurações teológicas e organizacionais atribuídas a grupos evangélicos pentecostais e neopentecostais, alguns balizadores fundamentais auxiliam no entendimento desse fenômeno transcultural e transnacional. 
Há uma constância no movimento evangélico, desde o surgimento dos primeiros grupos, no século XVI (como os Camisards, na França rural), até o ressurgimento do movimento em meio a operários do País de Gales e de comunidades afrodescendentes em Los Angeles (EUA): trata-se dos dons do Espírito Santo que aparecem no Novo Testamento a partir do Atos dos Apóstolos, onde se conta que os seguidores de Cristo foram batizados por uma língua de fogo que os marca com dons que os ajudariam a espalhar a palavra de seu mestre. Os dons mais citados são: glossolalia (a evocação de diferentes línguas, que supostamente seriam as línguas dos anjos), a cura com as mãos, a capacidade praticar exorcismos (expulsando demônios que tomam o corpo de pessoas), o dom da profecia, a interpretação de mensagens, o dom da sabedoria.

Esses dons acabam funcionando hoje, entre evangélicos, como signo de legitimação da conversão de um indivíduo. $\mathrm{O}$ aparecimento deles, e a forma como são usados em diferentes comunidades, varia bastante, compondo-se como marca das capacidades transculturais do movimento evangélico: com efeito, em certos países e entre algumas populações, como aquelas em que há uma proeminência de práticas animistas, os dons surgem como uma continuidade formal que permite ao movimento evangélico adentrar em 256 determinadas comunidades; já em outras, em que já há algum tipo de tradição cristã mais aferente ao campo social, o movimento evangélico surge se adequando a outros tipos de racionalidade do espaço social. Como exemplo desta última, podemos citar a Teologia da Prosperidade, onde a conversão de um sujeito se legitima por sua capacidade de conquistar uma boa saúde financeira, obter sucesso material, adquirir bens etc., algo que se coaduna com um capitalismo mais líquido e desregulado pelo poder público.

Não nos ateremos aqui a descrever as sutilezas e amarrações características do discurso evangélico e do funcionamento desses grupos, o que difere bastante ao redor do planeta e mesmo entre diferentes regiões num país como o Brasil, onde igrejas ocupam certos nichos em meio a classes sociais específicas (Vital da Cunha, 2008). Porém, muitos estudiosos insistem na relevância do "quadrilátero" proposto pelo historiador britânico David Bebbington (1989), que reconhece na variabilidade do movimento evangélico quatro atitudes/convicções constantes:

- conversão pessoal: o sujeito narra os efeitos da presença do Espírito Santo em sua vida, as transformações experimentadas, curas de doenças físicas ou de problemas psicológicos, evolução financeira;

- biblicismo: a centralidade da palavra contida na Bíblia, sem recursos ao metafórico ou à mediação exegética de autoridades e instituições; 
- engajamento pessoal: engajamento comunitário ao mundo evangélico, militantismo político ou moral, proselitismo (espalhar a palavra dos Evangelhos, converter o outro'), colocar seus "dons" a serviço da comunidade, como ser capaz de operar curas com as mãos, ter visões, decifrar profecias ou mensagens que aparecem em cultos ${ }^{3}$;

- crucicentrismo (centralidade da imagem de Cristo na cruz): fascinação pela figura de Cristo e de seu sofrimento, na ideia da batalha espiritual vivida por Jesus e dos fiéis no caminho para a salvação. Os evangélicos, como os protestantes reformistas, não têm estátuas de Jesus Cristo nu na cruz ou em outras representações, nem figuras como santos, a Virgem Maria $^{4}$ ou outros intermediários. Mesmo que essa proibição de imagens tenha servido para priorizar práticas religiosas com ênfase na experiência corporal do próprio fiel e de sua relação imediata com Cristo ou mesmo Deus, não é desinteressante notar que a cultura neopentecostal atual se serve de filmes (como a Paixão de Cristo, de Mel Gibson, 2004), séries, novelas (a programação da Rede Record nos últimos anos corrobora isso) e outras representações da vida de Cristo ou de histórias bíblicas como forma de evangelizar.

A circunscrição proposta por Bebbington aglutina uma variabilidade bem amarrada de fenômenos, resumindo a configuração de uma rede discursiva que pode auxiliar profissionais que trabalham com a subjetividade a apreender certos processos subjetivos aos quais estão atrelados pessoas e famílias que investem nesse tipo de religiosidade. Em linhas gerais, esse "cristianismo

${ }^{2}$ Um grupo que valoriza muito esse traço, o proselitismo, é o dos Testemunhas de Jeová, no qual trata-se como uma missão ir de porta em porta oferecer a palavra de Jeová e a "boa nova" trazida por Cristo. Os Testemunhas de Jeová que conhecemos ao longo de nossas pesquisas afirmam que sua fé se fortalece "a cada porta batida em suas caras".

${ }^{3}$ No caso de pacientes de saúde mental que frequentam igrejas evangélicas neopentecostais, é comum encontrarmos uma revalorização de alucinações auditivas ou visuais como signos e imagens de natureza profética. Ademais, já tivemos pacientes que se perguntavam se a voz que ouviam dentro de si seria Deus, Jesus, o demônio ou ainda alguma outra entidade ou espírito. Isso não se dá em outras igrejas reformadas, de um protestantismo mais clássico.

${ }^{4}$ Um dos episódios mais marcantes da chamada guerra das religiões pela cultura e pelo mercado religioso no Brasil foi o do "chute na Santa", protagonizado pelo pastor Sérgio von Helder, da Igreja Universal do Reino de Deus, no dia 12 de outubro 1995 (dia de Nossa Senhora Aparecida, figura de culto católica e padroeira do Brasil). Ao falar sobre a falsidade da adoração de objetos, imagens e figuras (prática comum no catolicismo), von Helder chutou repetidas vezes a imagem de Nossa Senhora durante o programa "Despertar da Fé", transmitido pela Rede Record. 
evangélico" é particularmente doutrinário, experencial e proponente de uma vivência cristã condensada e dura (Stewart, 2005). Entretanto, no caso do Brasil, o movimento neopentecostal vem centralizando sua teologia num discurso incendiário contra outras denominações religiosas contemporâneas, sobretudo as afro-brasileiras e o espiritismo (Gonçalves Silva, 2012).

De um ponto de vista demográfico e no que diz respeito ao mercado religioso, o constante ataque neopentecostal aos adeptos e práticas afrobrasileiras pareceria "muita pólvora para pouco passarinho" (ibidem). Porém, estrategicamente, ele faz sentido, já que o que está em jogo não é o avanço na cultura, mas uma tentativa de se propor como a configuração religiosa que monopolize algo caro a parcelas da sociedade brasileira: o mercado religioso das mediações mágicas, do transe religioso e da experiência do sagrado no próprio corpo. Demonizando tradições como a do candomblé e da umbanda, as autoridades evangélicas tentam garantir para si o poder de manipular soluções mágicas como o exorcismo ou o da força da palavra para operar rituais, curas e o próprio transe, visto que as religiões de matriz afro-brasileira sempre ocuparam um lugar privilegiado entre populações marginalizadas que encontravam nesse panteão mágico-religioso-discursivo uma potencialidade 258 de experiências (como a do transe e da proximidade com as deidades, a filiação a orixás) que as retirava de um lugar de submissão social.

\section{Impasses do discurso religioso: da teoria psicanalítica à transferência}

Retomamos um dos pontos axiais do ensino de Lacan (1954-55/1978), quando de sua investigação sobre o eu:

Freud descobriu no homem o peso e o eixo de uma subjetividade que ultrapassa a organização individual enquanto soma das experiências individuais, e mesmo enquanto linha do desenvolvimento individual. Eu vos dou uma definição possível da subjetividade ao formulá-la como sistema organizado de símbolos, pretendendo cobrir a totalidade de uma experiência, a animá-la, a dar sentido a ela. E o que nós tentamos fazer aqui senão uma subjetividade? As direções, aberturas, que são discutidas aqui sobre nossa experiência e nossa prática, são feitas para vos inspirar numa ação concreta. (p. 62; tradução nossa)

A coisa social, a coisa cultural e a coisa religiosa são eixos de subjetivação que estão além daquilo que se reduz à experiência individual. O que remete à religião contém os próprios germens da cultura e da subjetividade, 


\section{ARTIGOS}

advindo disso sua grande força. Olivier Roy (2008), teórico das religiões na globalização, é incisivo:

o "retorno" do religioso não passa de uma ilusão de ótica: deve-se falar em mutação. [...] Assistimos a uma reformulação do religioso e não a um retorno a práticas ancestrais que teriam decaído durante um parêntese de secularização. [...] o religioso se recusa a ser reduzido a um sistema simbólico entre outros. (p. 25; tradução nossa)

Tal assunção, de que a coisa religiosa se demarca de todo o caldeirão simbólico comum, remete às dificuldades de quando encontramos a coisa religiosa na concretude de nossas práticas. Recordamos ainda de uma outra comunidade onde trabalhamos num CAPS com grande número de pacientes que conviviam com sintomatologias psicóticas e com abuso de substâncias, especialmente álcool. Refratários aos planos de tratamento, inúmeros pacientes abandonavam suas medicações devido ao uso cruzado de álcool. Foi quando a instalação de uma pequena igreja evangélica, nessa comunidade quase rural e de grande distância de outros centros urbanos, a duas casas de distância do equipamento de saúde mental, provocou um estranho efeito: entre espaços de convivência e atendimentos no CAPS, vários pacientes passaram a frequentar a igreja. Nos finais de semana, aliás, eles se encontravam diante do portão do próprio serviço entre os cultos religiosos. Com o passar dos meses, pacientes antes refratários aos tratamentos aderiam às terapêuticas propostas. Num arroubo de curiosidade e surpresa, resolvemos discutir com o pastor responsável: "Vocês sabem que os pacientes de vocês melhoram muito mais quando se tornam nossos fiéis. Os que bebiam param e os remédios começam a fazer efeito. Eles se envolvem com a igreja, fazem trabalhos comunitários, deixam de ser vistos como loucos e perigosos. A gente conta com a força de Deus para salvar as pessoas, enquanto os profissionais do governo, da saúde, têm de usar os próprios músculos".

$\mathrm{O}$ argumento do pastor não deixa de evocar uma discussão antiga na própria psicanálise, e mesmo da própria psiquiatria. Quanto a esta última, cabe lembrar que em seu último escrito La foi qui guérit ( $A$ fé que cura, 1892/2015), publicado postumamente, Charcot se pergunta sobre a similitude entre as curas milagrosas experimentadas em locais de peregrinação religiosa, como Lourdes, e as curas de indivíduos acometidos por crises histéricas, nas quais o elemento da sugestão e da autossugestão seriam centrais para o dispositivo terapêutico. Como propunha o próprio Charcot, seriam "sujeitos especiais com doenças especiais, [...] em que o espírito possui o corpo” (p. 155; tradução nossa). Avançando nessa discussão, pode ser ressaltado não 
apenas os efeitos de crenças (mágico-religiosas) sobre a saúde, o corpo ou a vida psíquica, mas também sobre as incidências do discurso, seja o discurso religioso, da cultura, o científico, em suma, o discurso do Outro e seus efeitos sobre o sujeito.

No caso do discurso religioso e de seus "poderes", o apontamento de Charcot se refere a algo que logo habitava as preocupações de Freud (1905) e seguidores no tocante à estrutura da técnica e da ética do escopo psicanalítico: ao tratamento psíquico proposto pela psicanálise corresponderia não somente o "tratamento das manifestações mórbidas da vida anímica, [...] [mas também que o] "tratamento psíquico" denota o tratamento desde a alma, um tratamento - de transtornos anímicos tanto como corporais - com meios que atuam direta e imediatamente sobre o anímico do ser humano" (p. 1014; tradução nossa).

Numa das cartas ao pastor suíço Oskar Pfister, amigo e correspondente de Freud por trinta anos (1909-1939), o pai da psicanálise comparara as facilidades transferenciais que um pastor teria em comparação com um psicanalista: "Vocês têm a felicidade de conduzir a transferência até Deus e de restabelecer assim esse tempo abençoado - ao menos quanto a esse ponto

260 - em que a fé religiosa estufava as neuroses" (carta de Freud a Pfister de 9 de fevereiro de 1909, Freud, 1966, pp. 46-47; tradução nossa). Na mesma carta, Freud ressalta que a psicanálise, em si, não é religiosa ou arreligiosa, mas que ela apenas contribui na redução do sofrimento das almas.

\section{Considerações finais}

Em que medida um tratamento psicanalítico permitiria localizar no sofrimento de um ser, numa construção psicopatológica, que elementos religiosos contribuem para algum tipo de mal-estar ou de conflitos? Para Hirt (2007), psicanálise e religião agem sobre o mesmo espaço da realidade psíquica, contudo, cada uma traduz à sua guisa esse espaço, ali onde despontam os significantes e o arcabouço simbólico-imaginário que se dá entre psiquismo e sociedade, cultura e civilização. A relação entre psicanálise e religião não deve ser pensada a partir da posição de poder e de abertura à sugestão que o sujeito que se submete (seja à psicanálise ou a práticas religiosas), mas quanto à diferença que ambas estabelecem na relação entre saber e verdade.

Em "Moisés e o monoteísmo" (1939), Freud apontara que o acréscimo do monoteísmo à humanidade foi de guardar uma relação de adoração a um 
pai, um objeto irrepresentável, marcando uma passagem entre aquilo que seria do sensível (Sinnlich) para o espiritual (Geistlich). Freud via nisso um ganho (que poderíamos considerar como um ganho lógico-cognitivo-afetivo nas estruturas sociais de pensamento e da própria cultura, como sugeria Marcel Mauss), tendo em vista que o objeto (que, adorado, liga os fiéis) pode ser um objeto ausente, marcando uma transformação no simbólico e na cultura.

Tal operação é sucedânea do poder de consolação e de manejo com o desamparo que o próprio Freud localizou como o grande poder da coisa religiosa na cultura e na vida psíquica (Freud, 1927/2011 e 1930/2015). A partir das elucubrações de Jacques Lacan, especialmente em sua conferência $O$ triunfo da religião (2005), o que se pode acrescentar, quanto a essa posição da relação entre saber e verdade, à lida com o desamparo estrutural da cultura e da vida psíquica e também da centralidade do negativo no simbólico, é que a religião age nesse mesmo espaço da subjetividade, um espaço de falta, que também é o espaço, essa abertura, um sintoma, insistia Lacan, que permite à psicanálise aparecer.

Ora, a psicanálise faz parte desse mal-estar da civilização evocado por Freud. Por isso, um retorno do religioso, do tipo de sentido "secretado" pelo religioso a partir da ampliação do mal-estar no contemporâneo, poderia levar a um recalque da própria psicanálise, qual seja, do tipo de manejo do não sentido que é um dos horizontes de sua prática, de sua ética para com as coisas do homem, da cultura e da civilização.

Lacan indica ainda o paradoxo de uma coexistência entre psicanálise e religião na subjetividade atual: a psicanálise aposta nas consequências de pensar o operar sobre o sujeito falante, o parlêtre, o homem animal falante que fabrica para si essa atividade de falar, em toda sua imprevisibilidade, na medida em que os sintomas e o gozo do sujeito aparecem na "manifestação do real" para nós, seres vivos (Lacan, 2005, p. 93), já a religião se utiliza do Verbo para fechar toda essa invasão de real, o gozo cuja marca fundamental é a da inevitável insatisfação do desejo. Por isso, o que a religião opera e Lacan falava de um tipo muito específico de religião, a cristã - concerne o uso de nossa relação de fascinação gozosa com objetos que nos tomam e que fecham esse aparecimento da falta, recalcando à força, ou, nas palavras do próprio Lacan, recalcando pelo afogamento do sentido e pelo aparecimento de gadgets, de objetos efêmeros de satisfação que obliteram a marca central de nossa subjetividade, a falta.

Nas religiosidades atuais, observa-se um predomínio de práticas cujo artifício operacional é o da bricolagem: misturam-se pedaços de discursos, formas de interpretação, recursos simbólicos, teias imaginárias. Isso segmenta 
a experiência religiosa num tipo de vivência de satisfação sensorial, privada, que se coaduna com as políticas neoliberais contemporâneas (Hervieu-Léger, 1999), que prometem um fim da falta pelo consumo. Nesse ínterim, a gestão do sofrimento neoliberal também se torna uma das facetas privilegiadas de diferentes movimentos religiosos, o que é particularmente presente nos movimentos evangélicos neopentecostais, e toda as suas construções discursivas e políticas que passam pela chamada Teologia do Domínio e da Prosperidade: a vivência da religiosidade, sua legitimidade, é ancorada no ganho físico, na expansão da riqueza pessoal, da potência.

O que notamos nos casos que escolhemos diz desse direcionamento político-subjetivo privilegiado pelas religiões atuais. Há nelas um apelo a um tipo de procedimento que aponta ao gozo fálico, naquilo que Lacan pensou como sendo uma das vicissitudes da experiência mística: é um procedimento em que o signo do Outro, aquele que garantiria a legitimidade da coisa religiosa, passa pelo sensorial, por afetos e pelo sentido que se sedimentam numa experiência corpórea, seja pela presença e predominância do corpo da experiência religiosa, seja pela primazia de uma ligação à massa que aponta uma espécie de gozo fálico, num fechamento da alteridade.

Contudo, esse procedimento é capturado pelo efeito de sutura do parlêtre, deixando o sujeito se afogar num excesso de sentido. Trata-se de um impasse do discurso religioso na atualidade, na medida em que algo inerente a muitos dos movimentos religiosos da história da humanidade, que é a experiência mística (e sua relação de abertura total para com a alteridade), é utilizada, mas a fim de fechar a experiência de alteridade e da própria falta que caracteriza o desejo.

Os movimentos religiosos atuais, e isso parece-nos particularmente acurado para falar sobre o tipo de gestão do ser e do sofrimento que é proposto por esses movimentos neocristãos atuais (seja os evangélicos pentecostais, neopentecostais, carismáticos, os diferentes tipo de cristãos messiânicos) passam por um excesso de sentido e por uma experiência de adequação a uma massa, grudando a experiência do sujeito a um tipo de gestão do corpo, da moral, da relação com o outro. Temos aí muitas consequências políticas e sociais, algo que se agrava em países como o Brasil, onde a fraqueza do Estado deixa muitas aberturas para que esse tipo de discurso seja evocado por grupos que chegam ao poder.

Nas vinhetas apresentadas, é marcante a presença da coisa religiosa como que decalcando algo que dizia, incialmente, de problemáticas biográficas e psicopatológicas dos sujeitos: as alucinações de Joel, as itinerâncias de 
cura mágica tentadas pela avó; quanto ao caso de Jane, podemos citar tanto a transmissão de dom religioso que vinha da mãe e do avô como também a forma com que sua vida foi se moldando para dar cabo das profecias de sua mãe.

Em seguida, ambos os casos têm a marca de um desajuste institucional para pensar a religião na vida dos sujeitos e de como elementos religiosos faziam parte da fabricação dos sintomas que se apresentavam: basta mencionar o material que o Joel trazia no discurso, o que vivia em seu corpo e as encenações que repetia no espaço de convivência do CAPS, reencenando algo do vivido numa tentativa infinita de cura. Quanto a Jane, o mais saliente era aquilo que ela produzia em relação a seus cuidadores, particularmente seu terapeuta, que viveu fenômenos contratransferenciais intensos.

Nos dois casos, foi a tomada em consideração dessa dimensão religiosa em discussões de equipe que ajudou a possibilitar que a palavra desses sujeitos fosse escutada de forma mais acolhedora, o que, aliás, é aquilo ao qual a psicanálise se propõe num espaço de cuidado, notadamente em instituição.

Podemos avançar e dizer que muitos psicanalistas já se debruçaram pelas religiosidades mais clássicas, como o cristianismo católico, o judaísmo e mesmo o islamismo. Apesar de termos estudos muito relevantes, a coisa religiosa ainda permanece um tanto estranha à nossa reflexão enquanto psicanalistas (ou profissionais que bebam nessa disciplina). A psicanálise não poderá jamais falar sobre a ontologia da coisa religiosa, sobre a existência de Deus, a sobrevivência da alma etc. contudo, o que é incontestável é validar que experiências espirituais e religiosas são manifestações inerentes da subjetividade humana (Splendore \& Blackwell, 2016). Ou seja, é necessário acolher falas e experiências cuja gramática seja aquela proposta por uma discursividade religiosa, e que as mesmas atravessem a experiência transferencial no trabalho em saúde mental, tanto para pensar o diagnóstico transferencial como também para uma espécie de aproveitamento de emergentes espirituais para a confecção de um espaço de vida singular para uma pessoa.

\section{Referências}

Aubrée, M. (2013, jan/jun.). Gênese e atualidade da noção durkheimiana de efervescência. Revista Pós Ciencias Sociais, 10(19), 15-30.

Bebbington, D. (1989). Evangelicalism in Modern Britain: A History from the 1730 s to the 1980s. London, UK: Routledge. 
Binkowski, G. (2015). Je deviens une autre personne: Conversion religieuse, psychopathologie et re-création biographique dans l'Évangélisme. Tese de doutorado em Psicologia. Université Paris 13 Sorbonne Paris Cité. Orientação do prof. Thierry Baubet.

Binkowski, G. \& Baubet, T. (2012, mars). Les "évangélistes" écoutés em clinique: un fait religieux entre reconstruction identitaire et processus psychique, Métisse - Lettre de l'Association Internationale d'Ethnopsychanalyse (AIEP), XXII(1).

Carneiro, C. (2018). O estudos dos casos múltiplos: estratégia de pesquisa em psicanálise e educação. Psicologia USP, 29(2), 314-321.

Charcot, J.-M. (2015). La foi qui guérit. Paris, FR: Éditions Payot \& Rivages. (Trabalho original publicado em 1892).

De Chalus, A. (2014, jun.). Au Brésil, les évangéliques sur le terrain. La Croix. Recuperado de <https://www.la-croix.com/Archives/2014-06-28/Au-Bresil-lesevangeliques-sur-le-terrain.-ENQUETE.-Au-Bresil-les-evangeliques-sur-leterrain-2014-06-28-1171393>.

Dufour, D.-R. (2005). On achève bien les hommes. De qualques conséquences actuelles et futures de la mort de Dieu. Paris, FR: Denoël.

Fath, S. (2006). Le buteur brésilien qui 'parle toujours de Dieu'. Blog de Sébastien Fath. Recuperado de: <http://blogdesebastienfath.hautetfort.com/ archive/2006/06/24/le-buteur-bresilien-qui-parle-toujours-de-dieu.html>.

Freire Costa, J. (1989). Psicanálise e contexto cultural. Imaginário psicanalítico, grupos e psicoterapias. Petrópolis, RJ: Campus.

Freud, S. (1905). Psicoterapia (Tratamento por el espiritu). In Obras Completas (tomo 1; pp. 1014-1027). Buenos Aires: El Ateneo.

Freud, S. (1912). La dynamique du transfert. In La technique psychanalytique (pp. 50-60). Paris, FR: PUF.

Freud, S. (1939). L'homme Moïse et la religion monothéiste. In Écrits philosophiques et littéraires. Paris, FR: Seuil.

Freud, S. (1966). Correspondance avec le pasteur Pfister. 1909-1939. Paris, FR: Gallimard.

Freud, S. (2011). L'avenir d'une illusion. Paris, FR: Points. (Trabalho original publicado em 1927).

Freud, S. (2015). Le malaise dans la civilisation. In Écrits philosophiques et littéraires. Paris, FR: Seuil. (Trabalho original publicado em 1930).

Gonçalves da Silva, V. (2012). Concepções religiosas afro-brasileiras e neopentecostais: uma análise simbólica. In J. B. B. Pereira (Org.). Religiosidade no Brasil (pp. 219-256). São Paulo, SP: EDUSP. 


\section{ARTIGOS}

Hervieu-Léger, D. (1999). Le pèlerin et le converti. La religion en mouvement. Paris, FR: Flammarion.

Hirt, J.-M. (2006). Les trois despotes et l'infidèle. Cliniques Méditerranéennes, 73, 9-23, 2006/1.

Hirt, J.-M. (2007). La psychanalyse entre athéisme freudien et ouverture à l'écoute de "l'évènement intérieur" du sujet. Conferência no Cycle Psychanalyse et Spiritualités - Lyon, Quatrième Groupe (Organisation Psychanalyse de Langue Française). Recuperado de: <https://www.quatrieme-groupe.org/pdf/ pdf_01075LEPSY.pdf>.

Lacan, J. (1966). Situation de la psychanalyse et formation du psychanalyste em 1956. In Écrits (pp. 459-492). Paris, FR: Seuil. (Trabalho original publicado em 1956).

Lacan, J. (1975). Le séminaire. Livre XX. Encore. Paris, FR: Seuil. (Trabalho original publicado em 1972-73).

Lacan, J. (1978). Le séminaire. Livre II. Le moi dans la théorie de Freud et dans la technique de la psychanalyse. Paris, FR: Seuil. (Trabalho original publicado em 1954-55).

Lacan, J. (2005). Le triomphe de la religion. Précédé de Discours aux catholiques. Paris, FR: Seuil.

Mercier, J. (2012). L’identité protestante. In Le Monde Hors Série - L'atlas des religions édition 2012. Paris, FR: Le Monde.

Plunkett, P. (2009). Les évangéliques à la conquête du monde. Paris, FR: Perrin.

Rosa, M. D. (2016). A clínica psicanalítica em face da dimensão sociopolítica do sofrimento. São Paulo, SP: Escuta.

Roy, O. (2008). La Sainte Ignorance. Le temps de la religion sans culture. Paris, FR: Seuil.

Safatle, V. (2018). O circuito dos afetos. Corpos políticos, desamparo e o fim do indivíduo. Belo Horizonte, MG: Autêntica.

Siqueira, E. R. A., \& Queiroz, E. F. (2014). O singular do caso clínico: uma proposta metodológica em psicanálise. Arquivos Brasileiros de Psicologia, 66(3), 104-114.

Splendore, L., \& Blackwell, S. (2016). Investigação das experiências espirituais e religiosas na psicose. In Conselho Federal de Psicologia, Na fronteira da psicologia com os saberes tradicionais: práticas e técnicas (Vol. 2; pp. 53-59). São Paulo, SP: CRP.

Stewart, K. (2005). Did evangelicalism predate the eighteenth century? An examination os David Bebbington's thesis. Evangelical Quarterly, 77(2), 135-153.

Vital da Cunha, C. (2008). "Traficantes evangélicos": novas formas de experimentação do sagrado em favelas cariocas, Plural, 15, 23-46. 


\section{Resumos}

(Evangelical discourse and some of its effects: social bond, psychopathology and theoretical and trasnferential impasses)

This article discusses the presence of the evangelical discourse among patients of mental health and psychosocial care services, the features of that religious phenomenon and its potential to transform the lives of individuals, families and groups by linking them to a fairly peculiar modality of religious discourse. As our research took place in France and in Brazil, we propose two clinical vignettes (from one case in each country) to analyze the kind of subjective and psychic transformation caused by that religious bond, how it affects transference and the difficulties that it may cause for professionals who act on subjectivity. To achieve that goal, we surveyed some of the nodal points of psychoanalytic readings on religion and religiosity, on what results from the religious thing in the genesis of psychic life, in the subject, in groups, in culture and in politics.

Key words: Evangelicals, psychoanalysis, religion, conversion

(La discursivité évangélique et certains de ses effets: lien social, psychopathologie et impasses théoriques et transférentielles)

Dans cet article nous discutons la présence du discours évangélique parmi les patients de services de santé mentale et des soins psychosociaux, les caractéristiques de ce phénomène religieux et ses possibilités de transformer la vie des individus, des familles et des groupes en les liant à une modalité assez particulière de discursivité religieuse. Ayant étudié ce phénomène en France et au Brésil, nous proposons deux vignettes cliniques (un cas dans chaque pays) pour réfléchir sur le type de transformation subjective et psychique que ce lien religieux provoque, en quoi il affecte le transfert et sur les difficultés que cela peut créer pour les professionnels de la subjectivité. Pour ce faire, nous soulevons quelques points nodaux des lectures psychanalytiques sur la religion et la religiosité, sur ce qui ressort de la chose religieuse dans la genèse de la vie psychique, dans le sujet, dans les groupes, dans la culture et dans le politique.

Mots clés: Évangéliques, psychanalyse, religion, conversion

(El discurso evangélico y algunos de sus efectos: enlace social, psicopatología y cuestiones teóricas y transferenciales)

En este artículo, discutimos la presencia del discurso evangélico entre pacientes de servicios de salud mental y de atención psicosocial, en las características de tal fenómeno religioso y de sus posibilidades para transformar la vida de sujetos, familias y grupos al conectarlos a una modalidad bastante peculiar de discursividad religiosa. Como hemos venido investigando estas cuestiones en Francia y en el 


\section{ARTIGOS}

Brasil, proponemos dos viñetas clínicas (de un caso acompañado en cada uno de esos países) para pensar sobre el tipo de transformación subjetiva y psíquica que provoca ese vínculo religioso, en cómo afecta el enlace transferencial y en las dificultades que el mismo puede provocar para profesionales que actúan sobre la subjetividad. Para ello, levantamos algunos de los puntos nodales de las lecturas psicoanalíticas sobre religión y religiosidad, en lo que aparece de la cosa religiosa en la génesis de la vida psíquica, en el sujeto, en los grupos, en la cultura y en la política.

Palabras-clave: Evangélicos, psicoanálisis, religión, conversión

Citação/Citation: Binkowski, G. I., Rosa, M. D., \& Baubet, T. (2020, junho). A discursividade evangélica e alguns de seus efeitos: laço social, psicopatologia e impasses teóricos e transferenciais. Revista Latinoamericana de Psicopatologia Fundamental, 23(2), 245-268. http://dx.doi.org/10.1590/1415-4714.2020v23n2p245.6.

Editora/Editor: Profa. Dra. Ana Maria G. R. Oda

Submetido/Submitted: 27.6.2019 / 6.27.2019 Revisado/Revised: 18.5.2020 /5.18.2020

Aceito/Acepted: 24.5.2020 / 5.24.2019

Copyright: @ 2009 Associação Universitária de Pesquisa em Psicopatologia Fundamental/ University Association for Research in Fundamental Psychopathology. Este é um artigo de livre acesso, que permite uso irrestrito, distribuição e reprodução em qualquer meio, desde que o autor e a fonte sejam citados / This is an open-access article, which permits unrestricted use, distribution, and reproduction in any medium, provided the original authors and sources are credited.

Financiamento/Funding: Este trabalho recebeu apoio da Fundação de Apoio à Pesquisa do Estado de São Paulo - Fapesp (São Paulo, SP, Br) / This work is supported by Fundação de Apoio à Pesquisa do Estado de São Paulo - Fapesp (São Paulo, SP, Br).

Conflito de interesses/Conflict of interest: Os autores declaram que não há conflito de interesses. / The authors declare that there is no conflict of interest.

Gabriel InTICHeR BINKowski

Psicanalista e Psicólogo; Mestre em Clínica Transcultural e Doutor em Psicologia pela Université Paris 13 - Sorbonne (Paris, França); Pós-Dourorando no PPG de Psicologia Clínica da Universidade de São Paulo - USP (São Paulo, SP, Br); Membro do Laboratório 
de Psicanálise, Sociedade e Política (São Paulo, SP, Br) e da Unité Transversale de Recherche Psychogenèse et Psychopathologie (Paris, França).

Av. Professor Mello de Morais, 1721 - Butantã

05508-030 São Paulo, SP, Br

gabriel.binkowski@gmail.com

https://orcid.org/0000-0003-4908-9221

\section{Miriam Debieux Rosa}

Psicanalista; Professora Livre-Docente de Psicologia Clínica na Universidade de São Paulo - USP (São Paulo, SP, Br); Diretora do Laboratório de Psicanálise, Sociedade e Política (IP-USP; São Paulo, SP, Br).

Av. Professor Mello de Morais, 1721 - Butantã

05508-030 São Paulo, SP, Br

debieux@terra.com.br

https://orcid.org/0000-0002-9518-0424

\section{Thierry Baubet}

Psiquiatra; Professor de psiquiatria da infância e da adolescência na Université Paris 13 Sorbonne (Paris, França); Chefe do serviço de Psiquiatria da infância e da adolescência, psiquiatria geral e adictologia especializada do Hôpital Avicenne (Bobigny, França).

125 , rue de Stalingrad

93000 Bobigny, França

thierry.baubet@aphp.fr

https://orcid.org/0000-0002-4112-1592

This is an open-access article, which permits unrestricted use, distribution, 